\title{
A hospital-based analysis of pseudomeningoceles after elective craniotomy in children: what predicts need for intervention?
}

\author{
Sebastian P. Norrdahl, MS, ${ }^{1}$ Tamekia L. Jones, PhD, ${ }^{2-4}$ Pooja Dave, ${ }^{5}$ David S. Hersh, MD, ${ }^{6,7}$ \\ Brandy Vaughn, RN, ${ }^{7}$ and Paul Klimo Jr., MD, MPH ${ }^{6-8}$
}

${ }^{1}$ College of Medicine and Departments of ${ }^{2}$ Pediatrics and ${ }^{3}$ Preventive Medicine, University of Tennessee Health Science Center, Memphis; ${ }^{4}$ Children's Foundation Research Institute, Memphis; ${ }^{5}$ Rhodes College, Memphis; ${ }^{6}$ Department of Neurosurgery, University of Tennessee Health Science Center, Memphis; ${ }^{7}$ Le Bonheur Children's Hospital, Memphis; and ${ }^{8}$ Semmes Murphey, Memphis, Tennessee

OBJECTIVE In pediatric patients, the development of a postoperative pseudomeningocele after an elective craniotomy is not unusual. Most will resolve with time, but some may require intervention. In this study, the authors analyzed patients who required intervention for a postoperative pseudomeningocele following an elective craniotomy or craniectomy and identified factors associated with the need for intervention.

METHODS An institutional operative database of elective craniotomies and craniectomies was queried to identify all surgeries associated with development of a postoperative pseudomeningocele from January 1, 2010, to December 31 , 2017. Demographic and surgical data were collected, as were details regarding postoperative events and interventions during either the initial admission or upon readmission. A bivariate analysis was performed to compare patients who underwent observation with those who required intervention.

RESULTS Following 1648 elective craniotomies or craniectomies, 84 (5.1\%) clinically significant pseudomeningoceles were identified in 82 unique patients. Of these, $58(69 \%)$ of the pseudomeningoceles were diagnosed during the index admission (8 of which persisted and resulted in readmission), and 26 (31\%) were diagnosed upon readmission. Forty-nine patients (59.8\% of those with a pseudomeningocele) required one or more interventions, such as lumbar puncture(s), lumbar drain placement, wound exploration, or shunt placement or revision. Only race $(p<0.01)$ and duraplasty $(p=0.03$, OR 3.0) were associated with the need for pseudomeningocele treatment.

CONCLUSIONS Clinically relevant pseudomeningoceles developed in $5 \%$ of patients undergoing an elective craniotomy, with $60 \%$ of these pseudomeningoceles needing some form of intervention. The need for intervention was associated with race and whether a duraplasty was performed.

https://thejns.org/doi/abs/10.3171/2019.11.PEDS19227

KEYWORDS pseudomeningocele; elective craniotomy; intervention; treatment; risk factors; hydrocephalus

\begin{abstract}
A PSEUDOMENINGOCELE is defined as an abnormal collection of CSF bounded by extradural soft tissue. It is a well-known possible sequela of any intradural cranial or spinal surgery. For example, in a randomized trial of 229 adults undergoing elective craniotomy, the pseudomeningocele rate ranged from $9.7 \%$ to $17.2 \%$, with diabetes mellitus, elevated preoperative C-reactive protein level, and duraplasty being positively associated with pseudomeningocele occurrence. ${ }^{9}$ A recent systematic review reported a pseudomeningocele rate of around $8 \% .^{10}$
\end{abstract}

In recent years, several attempts have been made to identify patient or surgical factors that influence the patient's risk of developing a pseudomeningocele following cranial surgery. Numerous variables have been examined, including surgical location and technique, use of various dural grafts or tissue sealants, patient demographics, and presurgical diagnoses. ${ }^{4,5,7,11,13,14,16,18,21,22}$ The results of these studies have been largely inconclusive, with craniectomies being the most commonly cited predictor of pseudomeningocele development. ${ }^{4,5,7,14}$ However, previous studies have 
almost exclusively focused on a specific anatomical location, namely the posterior fossa. ${ }^{4-7,11,13,14,16,18,21,22}$ Additionally, few studies have focused on the pediatric population.

Most pseudomeningoceles are self-limiting. ${ }^{15,23} \mathrm{Howev-}$ er, those that are large, growing, or symptomatic with concomitant hydrocephalus will likely require one or more interventions, including lumbar puncture, surgical drainage and repair, and shunt placement. Tu et al. explored physician preferences with regard to pseudomeningocele treatment. ${ }^{23}$ Although overall there was no consensus or standardized protocol as to the type and timing of treatment, the majority of respondents wait at least 7-14 days before exploring a posterior fossa pseudomeningocele following tumor resection.

To our knowledge, predictors of pseudomeningocele intervention-as opposed to development-have not been previously investigated. The purpose of this study was to explore the association between previously cited variables, in addition to several novel ones, and the need to treat a clinically significant pseudomeningocele in the hospital setting.

\section{Methods \\ Database Creation}

An institutional (Le Bonheur Children's Hospital) operative database of elective craniotomies and craniectomies that is retrospectively maintained on a regular basis was queried to identify all surgeries associated with the development of postoperative pseudomeningoceles from January 1, 2010, to December 31, 2017. An index operation was defined as any independent elective (i.e., nonurgent or emergent) craniotomy or craniectomy. As such, one patient may have had more than one index operation. In order for patients to be included in this analysis, their pseudomeningocele(s) must have been diagnosed within the first 90 days of their index surgery, whether during the initial hospitalization or during readmission, or both. As such, each patient had at least one index surgery and 0-3 readmissions.

\section{Variables and Definitions}

A pseudomeningocele was defined as a "clinically significant" (i.e., visible or palpable by physical examination, as documented in the electronic medical record) CSF collection, contained within extradural cranial or upper cervical soft tissues, with or without a CSF-cutaneous fistula (i.e., CSF leak through the recent skin incision). Clinically insignificant or irrelevant subcutaneous fluid collections were defined as those that were not detectable by physical examination (i.e., diagnosed by imaging only). Our primary outcome was need for treatment, defined as any and all procedures (bedside or in the operating theater) directed at reducing the size and ultimately eliminating the patient's pseudomeningocele. Each surgeon was free to choose the type and timing of intervention (i.e., no specific management protocol was followed).

Demographic, clinical, and surgical details regarding the index hospitalization and any readmission were collected. Several historical variables pertinent to the index admission were noted, including history of prior craniot- omy and the location of the previous surgical site relative to the index procedure (i.e., same site or different), hydrocephalus history (existing shunt or prior endoscopic third ventriculostomy [ETV]), and prior exposure to cranial irradiation. Index procedural variables included whether the operation was a craniotomy or craniectomy, type of procedure, location of procedure (supratentorial vs infratentorial), and whether a dural patch graft was used. Dural grafts are routinely applied to the native dura by suture rather than onlay, especially for posterior fossa surgery. Procedure types included tumor resection (supratentorial or infratentorial), craniosynostosis, seizure surgery (subdural grid placement or resection of seizure focus), Chiari decompression, and vascular surgery of any kind, as well as the category of "other." Tumors were further categorized into specific tumor types. Finally, several postoperative complications relevant to pseudomeningoceles were recorded, such as bacterial meningitis, CSF leak, hydrocephalus, and wound infection, the latter being defined as having positive representative cultures obtained from the wound. Any and all interventions that were needed to definitively address the pseudomeningocele were noted.

\section{Study Questions}

With this retrospective observational study, we sought to answer the following two questions: 1) What are the characteristics of the cohort who developed a clinically significant pseudomeningocele following an elective craniotomy or craniectomy? 2) What variables are associated with the need for pseudomeningocele treatment?

\section{Statistical Analysis}

Demographic, clinical, and surgical variables were summarized using frequency and percentages for categorical variables and mean and range for continuous variables. Odds ratio (OR) estimates and 95\% confidence intervals (CIs) were generated using generalized estimating equations with an independent correlation structure to examine associations between each variable and the outcome of treatment versus no treatment of pseudomeningocele. Due to the small ratio of the number of observations in each outcome category to the number of variables, only bivariate analyses were conducted, in accordance with the proposed rules for events per variable set forth by Peduzzi et al. ${ }^{17}$ and Wynants et al. ${ }^{24}$ Statistical significance was defined as $p<0.05$. All analyses were performed using SAS software version 9.3 (SAS Institute Inc.).

\section{Results}

Of the 1648 elective craniotomies or craniectomies performed from January 1, 2010, to December 31, 2017, $84(5.1 \%)$ resulted in a postoperative pseudomeningocele, with $58(69 \%)$ diagnosed during the index admission and 26 (31\%) during the readmission. Eight patients developed pseudomeningoceles during the index admission that persisted to readmission. All readmissions occurred within 30 days of discharge following the index surgery. Thirty-four index surgeries $(40.5 \%)$ were followed by at least 1 readmission, of which $2(2.4 \%)$ required a second readmission and $2(2.4 \%)$ required a third readmission to 
TABLE 1. Demographics and prior treatment information

\begin{tabular}{|c|c|c|c|}
\hline Patient Variable & $\begin{array}{l}\text { All Pseudomeningoceles } \\
\qquad(n=84)\end{array}$ & $\begin{array}{l}\text { No Intervention } \\
\quad(n=34)\end{array}$ & $\begin{array}{l}\text { Intervention Required } \\
\qquad(n=50)\end{array}$ \\
\hline Age in yrs, mean (range) & $6.62(0.13-24.81)$ & $6.24(0.24-18.56)$ & $6.89(0.13-24.81)$ \\
\hline \multicolumn{4}{|l|}{ Age in yrs } \\
\hline$<5$ & $40(47.6 \%)$ & $17(50 \%)$ & $23(46 \%)$ \\
\hline $5-10$ & $27(32.1 \%)$ & $10(29.4 \%)$ & $17(34 \%)$ \\
\hline$>10$ & $17(20.2 \%)$ & $7(20.6 \%)$ & $10(20 \%)$ \\
\hline \multicolumn{4}{|l|}{ Sex } \\
\hline Male & $57(67.9 \%)$ & $22(64.7 \%)$ & $35(70 \%)$ \\
\hline Female & $27(32.1 \%)$ & $12(35.3 \%)$ & $15(30 \%)$ \\
\hline \multicolumn{4}{|l|}{ Race } \\
\hline Caucasian & $48(57.1 \%)$ & $17(50 \%)$ & $31(62 \%)$ \\
\hline African American & $17(20.2 \%)$ & $3(8.8 \%)$ & $14(28 \%)$ \\
\hline Hispanic & $6(7.1 \%)$ & $4(11.8 \%)$ & $2(4 \%)$ \\
\hline Other/unspecified & $13(15.5 \%)$ & $10(29.4 \%)$ & $3(6 \%)$ \\
\hline \multicolumn{4}{|l|}{ Insurance } \\
\hline None & $1(1.2 \%)$ & $1(2.9 \%)$ & $0(0 \%)$ \\
\hline Private & $50(59.5 \%)$ & $20(58.8 \%)$ & $30(60 \%)$ \\
\hline Government & $33(39.3 \%)$ & $13(38.2 \%)$ & $20(40 \%)$ \\
\hline \multicolumn{4}{|l|}{ Existing shunt } \\
\hline No & $76(90.5 \%)$ & $31(91.2 \%)$ & $45(90 \%)$ \\
\hline Yes & $8(9.5 \%)$ & $3(8.8 \%)$ & $5(10 \%)$ \\
\hline \multicolumn{4}{|l|}{ Prior ETV } \\
\hline No & $77(91.7 \%)$ & $31(91.2 \%)$ & $46(92 \%)$ \\
\hline Yes & $7(8.3 \%)$ & $3(8.8 \%)$ & $4(8 \%)$ \\
\hline \multicolumn{4}{|l|}{ Prior radiation } \\
\hline No & $76(90.5 \%)$ & $29(85.3 \%)$ & $47(94 \%)$ \\
\hline Yes & $8(9.5 \%)$ & $5(14.7 \%)$ & $3(6 \%)$ \\
\hline
\end{tabular}

Values are presented as number of pseudomeningoceles (\%) unless otherwise indicated.

resolve the pseudomeningocele. Demographics are summarized in Table 1. At the time of the index procedure, the mean patient age was 6.6 years (range $0.1-24.8$ years), and $57(65.9 \%)$ patients were male. The majority of children were Caucasian $(57.1 \%)$ with private insurance $(59.5 \%)$. A minority of patients had an existing shunt (9.5\%), had undergone prior ETV (8.3\%), or had previously received cranial irradiation $(9.5 \%)$.

\section{Index Surgery Characteristics}

Details of the index surgeries are summarized in Table 2. In 77 cases, the index procedure consisted of a craniotomy, while in 7 cases, the procedure was a craniectomy. In $35(41.7 \%)$ cases there was a prior craniotomy, and of these, the index surgery was performed at the same surgical site in $30(35.7 \%)$ cases. Duraplasty was performed in 32 cases $(38.1 \%, 14$ supratentorial and 18 infratentorial).

Index procedures were largely tumor resections (64 cases, $76.2 \%$ of the total sample), with 38 tumors $(59.4 \%$ of tumor resections) being supratentorial and 26 (40.6\% of tumor resections) infratentorial. Table 3 lists the various tumor types, with the 3 most common being pilocytic as- trocytoma or ganglioglioma $(\mathrm{n}=12 ; 18.8 \%)$, medulloblastoma $(\mathrm{n}=11 ; 17.2 \%)$, and "other" high-grade tumors ( $\mathrm{n}=$ $10 ; 15.6 \%)$. Additional index surgeries were craniotomies for epilepsy $(\mathrm{n}=13 ; 15.5 \%)$, Chiari decompressions $(\mathrm{n}=$ $3 ; 3.6 \%)$, and vascular procedures $(\mathrm{n}=1 ; 1.2 \%)$. Six operations were categorized as "other" (7.1\%).

\section{Pseudomeningocele and Associated Complications}

Isolated pseudomeningoceles, those without accompanying adverse events such as wound complications or meningitis, occurred after 61 operations - 41 were diagnosed during the initial hospitalization and 20 upon readmission. The remaining 23 pseudomeningoceles were diagnosed with one or more surgical postoperative events, as listed in Table 4 . The most common comorbidities were previously untreated hydrocephalus (8 instances during initial admission and 10 on readmission) and CSF-cutaneous fistulas (9 during initial admission and 9 on readmission).

\section{Intervention(s)}

On average, 1.29 procedures were performed at the index visit, while 2.27 were performed during readmission. 
TABLE 2. Index surgery details grouped by surgery location (supra- vs infratentorial)

\begin{tabular}{|c|c|c|c|}
\hline Variable & $\begin{array}{l}\text { All Pseudomeningoceles } \\
\qquad(n=84)\end{array}$ & $\begin{array}{l}\text { No Intervention } \\
\quad(n=34)\end{array}$ & $\begin{array}{l}\text { Intervention Required } \\
\qquad(n=50)\end{array}$ \\
\hline Supratentorial & $54(64.3 \%)$ & $26(76.5 \%)$ & $28(56 \%)$ \\
\hline \multicolumn{4}{|l|}{ Prior craniotomy } \\
\hline No & $28(51.9 \%)$ & $12(46.2 \%)$ & $16(57.1 \%)$ \\
\hline Yes, same location & $21(38.9 \%)$ & $10(38.5 \%)$ & $11(39.3 \%)$ \\
\hline Yes, different location & $5(9.3 \%)$ & $4(15.4 \%)$ & $1(3.6 \%)$ \\
\hline \multicolumn{4}{|l|}{ Procedure type } \\
\hline Craniotomy & $52(96.3 \%)$ & $25(96.2 \%)$ & $27(96.4 \%)$ \\
\hline Craniectomy & $2(3.7 \%)$ & $1(3.8 \%)$ & $1(3.6 \%)$ \\
\hline \multicolumn{4}{|l|}{ Duraplasty } \\
\hline No & $40(74.1 \%)$ & $22(84.6 \%)$ & $18(64.3 \%)$ \\
\hline Yes & $14(25.9 \%)$ & $4(15.4 \%)$ & $10(35.7 \%)$ \\
\hline \multicolumn{4}{|l|}{ Indication } \\
\hline Tumor resection & $38(70.4 \%)$ & $18(69.2 \%)$ & $20(71.4 \%)$ \\
\hline Seizure surgery & $13(24.1 \%)$ & $5(19.2 \%)$ & $8(28.6 \%)$ \\
\hline Other & $6(11.1 \%)$ & $3(11.5 \%)$ & $3(10.7 \%)$ \\
\hline Infratentorial & $30(35.7 \%)$ & $8(23.5 \%)$ & $22(44 \%)$ \\
\hline \multicolumn{4}{|l|}{ Prior craniotomy } \\
\hline No & $21(70 \%)$ & $5(62.5 \%)$ & $16(72.7 \%)$ \\
\hline Yes, same location & $9(30 \%)$ & $3(37.5 \%)$ & $6(27.3 \%)$ \\
\hline Yes, different location & $0(0 \%)$ & $0(0 \%)$ & $0(0 \%)$ \\
\hline \multicolumn{4}{|l|}{ Procedure type } \\
\hline Craniotomy & $25(83.3 \%)$ & $7(87.5 \%)$ & $18(81.8 \%)$ \\
\hline Craniectomy & $5(16.7 \%)$ & $1(12.5 \%)$ & $4(18.2 \%)$ \\
\hline \multicolumn{4}{|l|}{ Duraplasty } \\
\hline No & $12(40 \%)$ & $4(50 \%)$ & $8(36.4 \%)$ \\
\hline Yes & $18(60 \%)$ & $4(50 \%)$ & $14(63.6 \%)$ \\
\hline \multicolumn{4}{|l|}{ Indication } \\
\hline Tumor resection & $26(86.7 \%)$ & $7(87.5 \%)$ & $19(86.4 \%)$ \\
\hline Chiari decompression & $3(10 \%)$ & $0(0 \%)$ & $3(13.6 \%)$ \\
\hline Vascular & $1(3.3 \%)$ & $1(12.5 \%)$ & $0(0 \%)$ \\
\hline
\end{tabular}

Of the 58 pseudomeningoceles that developed during the initial hospitalization, $21(36.2 \%)$ required one or more of the following interventions: lumbar puncture $(\mathrm{s})(\mathrm{n}=10)$, shunt placement or revision $(n=7)$, wound exploration ( $n$ $=6)$, percutaneous aspiration $(\mathrm{n}=2)$, and lumbar drain placement $(\mathrm{n}=2)$. Of the 34 patients who were readmitted, $30(88.2 \%)$ required one or more of the following interventions for their pseudomeningoceles: wound exploration (n =24), lumbar puncture (s) ( $\mathrm{n}=16)$, lumbar drain placement $(n=11)$, shunt placement or revision $(n=10)$, and percutaneous aspiration $(\mathrm{n}=2)$.

In total, 30 (35.7\%) cases of pseudomeningocele required surgical wound exploration. Of these, complete resolution of the pseudomeningocele (i.e., definitive treatment) occurred in $16(53.3 \%)$ cases. In 14 cases, however, the patients required further treatment, primarily with shunting ( 9 cases) or lumbar drain placement ( 4 cases), and with 1 additional case requiring more extensive management with multiple interventions to achieve resolution. Of note, the latter case was the only case of the 14 that was managed at the index visit. All others required readmission to successfully treat the pseudomeningocele.

\section{Associations With Intervention}

The results of the bivariate analyses are shown in Table 5 , which models the probability that intervention of any kind was required. Of all the variables tested, only race $(\mathrm{p}=0.007)$ and duraplasty at index operation $(\mathrm{p}=0.03)$ were statistically significant. Caucasian children had 3.7 $(p=0.16)$ and $6.25(p=0.008)$ greater odds of requiring treatment than Hispanic patients and other/unspecified race patients, respectively. African American patients had 2.56 greater odds of requiring treatment than Caucasian patients, but this difference did not reach statistical significance $(p=0.18)$. Twenty-four of 50 pseudomeningoceles $(48 \%)$ that required intervention occurred following index procedures during which a duraplasty had been performed, compared with 8 of 34 pseudomeningoceles $(23.5 \%)$ that did not require intervention. Surgeries 
TABLE 3. Tumor details

\begin{tabular}{lccc}
\hline \multicolumn{1}{c}{ Variable } & $\begin{array}{c}\text { All } \\
\text { Pseudomeningoceles } \\
(\mathrm{n}=84)\end{array}$ & $\begin{array}{c}\text { No } \\
\text { Intervention } \\
(\mathrm{n}=34)\end{array}$ & $\begin{array}{c}\text { Intervention Required } \\
(\mathrm{n}=50)\end{array}$ \\
\hline Tumor present & & & \\
\hline No & $20(23.8 \%)$ & $9(26.5 \%)$ & $11(22 \%)$ \\
\hline Yes & $64(76.2 \%)$ & $25(73.5 \%)$ & $39(78 \%)$ \\
\hline Tumor type & & & $7(18 \%)$ \\
\hline Medulloblastoma & $11(17.2 \%)$ & $4(16 \%)$ & $6(15.4 \%)$ \\
\hline Ependymoma & $9(14.1 \%)$ & $3(12 \%)$ & $8(20.5 \%)$ \\
\hline Pilocytic astrocytoma or ganglioglioma & $12(18.8 \%)$ & $4(16 \%)$ & $1(2.6 \%)$ \\
\hline Craniopharyngioma & $5(7.8 \%)$ & $4(16 \%)$ & $4(10.3 \%)$ \\
\hline High-grade glioma & $6(9.4 \%)$ & $2(8 \%)$ & $3(7.7 \%)$ \\
\hline ATRT & $4(6.3 \%)$ & $1(4 \%)$ & $0(0 \%)$ \\
\hline Choroid plexus tumor & $1(1.6 \%)$ & $1(4 \%)$ & $7(18 \%)$ \\
\hline Other: high grade & $10(15.6 \%)$ & $3(12 \%)$ & $3(7.7 \%)$ \\
\hline Other: low grade & $6(9.4 \%)$ & $3(12 \%)$ & \\
\hline
\end{tabular}

ATRT = atypical teratoid rhabdoid tumor.

involving a duraplasty carried 3-fold odds $(\mathrm{p}=0.03)$ of resulting in a pseudomeningocele that needed intervention, compared with surgeries in which no duraplasty was performed. The surgical site demonstrated a nearly significant association, with supratentorial surgery having a decreased risk (OR $0.39 ; p=0.06)$ of leading to pseudomeningocele formation.

\section{Discussion}

CSF complications after elective cranial or spinal surgery in children-such as hydrocephalus, meningitis, and CSF leak-can cause significant morbidity, necessitating one or more interventions, prolonging hospitalization, prompting readmission, and adding to healthcare costs. ${ }^{1,20}$ While there is substantial literature that evaluates the risk of pseudomeningocele development, there is surprisingly little that deals with the risk of needing pseudomeningocele treatment. One cannot assume that variables associated with development would be the same for treatment. For neurosurgeons, we felt that the latter was the more clinically relevant question since most pseudomeningoceles will resolve on their own.

\section{Study Results}

The overall rate of developing a clinically relevant pseudomeningocele (i.e., one that was evident on physical examination) after an elective craniotomy or craniectomy was $5.1 \%$. Of these cases, $64 \%$ followed supratentorial surgery and $36 \%$ followed infratentorial surgery. Tumor resection was the predominant reason for surgery (64/84; $76 \%$ ) and the majority of these patients had high-grade pathology $(40 / 64 ; 63 \%)$. Almost all index surgeries were craniotomies as opposed to craniectomies $(77 / 84 ; 92 \%)$, and a duraplasty was performed in 38\% (32/84) of cases.

One of the most serious consequences of a pseudomeningocele is a CSF-cutaneous fistula, which demands urgent intervention to mitigate the risk of bacterial contamination. Those pseudomeningoceles that developed a leak $(n=18)$ were more likely to be treated with a major operative intervention (i.e., shunt or wound exploration) than were those without a leak, for which "bedside" procedures (i.e., lumbar puncture, lumbar drain, or percutaneous aspiration) were favored. In our series, bacterial meningitis and wound infection developed after 6 and 5 index operations, respectively. These patients often under-

TABLE 4. Surgical postoperative events

\begin{tabular}{lccc}
\hline \multicolumn{1}{c}{ Variable } & Index Surgery $(\mathrm{n}=58)$ & Readmission $(\mathrm{n}=34)$ & Total $(\mathrm{n}=84)^{*}$ \\
\hline Pseudomeningocele only & $41(70.7 \%)$ & $20(58.8 \%)$ & NA \\
\hline Pseudomeningocele with: & & & $6(7.1 \%)$ \\
\hline Bacterial meningitis & $4(6.9 \%)$ & $2(5.9 \%)$ & $5(6 \%)$ \\
\hline Wound infection & $0(0 \%)$ & $5(14.7 \%)$ & $18(21.4 \%)$ \\
\hline CSF leak & $9(15.5 \%)$ & $10(29.4 \%)$ & $18(21.4 \%)$ \\
\hline Hydrocephalus & $8(13.8 \%)$ & & \\
\hline $\begin{array}{l}\text { NA = not applicable. } \\
\text { * Total postoperative events. Eight patients developed pseudomeningoceles during their index admission that persisted } \\
\text { to readmission. }\end{array}$
\end{tabular}


TABLE 5. Bivariate analyses ( $n=84$ pseudomeningoceles)

\begin{tabular}{|c|c|c|}
\hline Variable & OR Estimate $(95 \% \mathrm{Cl})$ & p Value \\
\hline Age in yrs (continuous) & $1.02(0.94-1.11)$ & 0.56 \\
\hline Age in yrs (categorical) & & 0.90 \\
\hline$<5$ & $1.26(0.47-3.39)$ & 0.65 \\
\hline $5-10$ & $1.06(0.34-3.31)$ & 0.93 \\
\hline$>10$ & Reference & - \\
\hline \multicolumn{3}{|l|}{ Sex } \\
\hline Female & $0.79(0.32-1.95)$ & 0.60 \\
\hline Male & Reference & - \\
\hline Race & & 0.007 \\
\hline African American & $2.56(0.64-10.2)$ & 0.18 \\
\hline Hispanic & $0.27(0.05-1.66)$ & 0.16 \\
\hline Other/unspecified & $0.16(0.04-0.62)$ & 0.008 \\
\hline Caucasian & Reference & - \\
\hline \multicolumn{3}{|l|}{ Insurance } \\
\hline Government/none & $0.95(0.39-2.32)$ & 0.91 \\
\hline Private & Reference & - \\
\hline \multicolumn{3}{|l|}{ Existing shunt prior to index } \\
\hline Yes & $1.15(0.26-5.16)$ & 0.86 \\
\hline No & Reference & - \\
\hline \multicolumn{3}{|l|}{ ETV prior to index } \\
\hline Yes & $1.02(0.33-3.2)$ & 0.97 \\
\hline No & Reference & - \\
\hline \multicolumn{3}{|l|}{ Radiation prior to index } \\
\hline Yes & $0.37(0.08-1.63)$ & 0.19 \\
\hline No & Reference & - \\
\hline \multicolumn{3}{|l|}{ Prior craniotomy } \\
\hline Yes at same site & $0.83(0.34-2.05)$ & 0.69 \\
\hline No or yes but at different site & Reference & - \\
\hline \multicolumn{3}{|l|}{ Index: tumor resected } \\
\hline Yes & $1.28(0.46-3.51)$ & 0.64 \\
\hline No & Reference & - \\
\hline \multicolumn{3}{|l|}{ Index: craniectomy } \\
\hline Yes & $1.78(0.32-9.74)$ & 0.51 \\
\hline No & Reference & - \\
\hline \multicolumn{3}{|l|}{ Index: surgical site } \\
\hline Supratentorial & $0.39(0.15-1.03)$ & 0.06 \\
\hline Infratentorial & Reference & - \\
\hline \multicolumn{3}{|l|}{ Index: duraplasty } \\
\hline Yes & $3(1.14-7.89)$ & 0.03 \\
\hline No & Reference & - \\
\hline
\end{tabular}

went reoperations for one or more indications in addition to several weeks of intravenous antibiotics, all resulting in extended lengths of stay and increased cost.

Of our 84 pseudomeningocele events, 50 (60\%) required one or more interventions, either during the initial admission or upon readmission. The odds of receiving treatment were 13 times greater upon readmission than during the initial admission (88\% vs 36\%; $\mathrm{p}<0.0001)$, a reflection of the reluctance by the treating surgeon to im- mediately intervene in a case of an early postoperative pseudomeningocele or seroma with the hope that it will regress with time. Patients often underwent more than one intervention, with the overall rate being 1.76 procedures per pseudomeningocele. Most of the readmitted patients ( $\mathrm{n}$ $=30 ; 88.2 \%$ ) underwent some form of intervention during their initial hospital stay; 2 patients (2.4\% of full sample) were readmitted for a third time, and both received further intervention for their pseudomeningoceles during their third admission.

There is no standardized approach to patients with a postoperative pseudomeningocele within our group of surgeons, but several generalizations can be made. While management is generally dictated by the physical examination and imaging findings, a conservative attitude is often initially taken with the hope that the pseudomeningocele will improve sufficiently or completely resolve within a reasonable time period. Minor procedures (i.e., lumbar punctures, lumbar drains, and aspirations) can be of some use, but major procedures (i.e., shunt placement or revision and wound exploration) are more commonly performed when the pseudomeningocele is large or tense, is associated with a leak or hydrocephalus, or is the primary reason for readmission. It should be noted that some lumbar punctures were done in conjunction with other procedures, such as wound explorations, as a means not only to assess intracranial pressure, but also to fenestrate the dura of the lumbar cistern.

Patient characteristics in the group requiring intervention for their pseudomeningoceles were largely similar to those who underwent observation. Both patient groups exhibited a moderate male predominance, and those undergoing intervention were slightly older on average (6.9 years vs 6.2 years). The variable "race" was statistically significant in the bivariate analysis for association with pseudomeningocele treatment $(\mathrm{p}=0.007)$. While the only statistically significant comparison within this category was "other/unspecified" versus "Caucasian" (OR 0.16; p $<0.01$ ), there was a notable trend of African American patients having a greater risk than Caucasian patients of undergoing treatment (OR 2.56; $\mathrm{p}=0.18$ ). An explanation for this finding is not readily available, but it is possible that a family's preference could influence a surgeon's decision whether to treat a pseudomeningocele.

Duraplasty was the only other variable found to be associated with treatment (OR 3; $p=0.03)$. Surgical site was almost statistically significant $(\mathrm{p}=0.06)$, with an infratentorial pseudomeningocele having 2.56 greater odds of undergoing treatment. This finding makes clinical sense, and there is an interaction between surgical site and duraplasty, as the rate of duraplasty with infratentorial surgery was greater than that with supratentorial surgery $(60 \%$ vs $26 \%$ ). The importance of duraplasty emphasizes the need for meticulous technique in order to achieve as watertight of a closure as possible, especially with posterior fossa surgery. Various adjuncts have been investigated, from the type of dural graft or sealant used to whether the bone flap was replaced or the type of wound closure used (e.g., myofascial cuff technique), but in our opinion, there is no substitute for careful closure of the dura, done in conjunction with the various soft-tissue layers (muscle, fascia, ga- 
lea, and skin). ${ }^{3}$ The same degree of attention given to the reason for the operation itself should be paid to wound closure; it should not be automatically relegated to a trainee without proper instructions or supervision.

\section{Literature}

There are no studies, to our knowledge, that are directly comparable to ours. A series of 105 posterior fossa tumor resections from 1982 to 1992 resulted in 5 patients (4.8\%) developing a pseudomeningocele "requiring additional treatment." 2 Previous studies have examined the development of pseudomeningoceles in Chiari patients, but neither explored predictors of intervention. ${ }^{13,16}$ There were only 3 patients with Chiari malformation in our series and all underwent intervention. Previous studies have reported a significant association between craniectomies and pseudomeningocele development, but like the Chiari studies, these did not examine variables associated with intervention. ${ }^{4,5}$ In our series, 5 of 7 craniectomy patients underwent intervention for their pseudomeningoceles, but no significant difference was found between groups. The small number of craniectomies in our sample makes this factor difficult to evaluate.

A recent study by Roth et al. ${ }^{19}$ included patients with features similar to those of our cohort. Among 163 craniotomies, $74 \%$ were supratentorial, $74 \%$ were for tumor resections, $96 \%$ had a dural substitute, and $89 \%$ were considered to have a nonwatertight dural closure. The authors found that the only variable significantly associated with pseudomeningocele development or the need for CSF diversion was an infratentorial location..$^{19}$

If we assume that the development of a postoperative CSF leak is always an indication for some form of intervention, then there is some comparable literature. In a consecutive series of 211 children who underwent 273 craniotomies for tumors, Lassen et al. reported a CSF leak rate of $7.3 \% ; 1.8 \%$ of their cases developed an isolated pseudomeningocele requiring treatment..$^{12}$ Variables associated with a CSF-cutaneous fistula were age $<3$ years $(\mathrm{p}<0.01)$, female sex (OR 0.36; $\mathrm{p}<0.05$ ), infratentorial surgery (OR 2.67; $\mathrm{p}<0.05$ ), and untreated preoperative hydrocephalus (OR 5.16; $\mathrm{p}<0.001$ ). Repeat craniotomy, as in our study, was not predictive. The same group published another analysis several years later, now with 381 craniotomies for tumor and a multivariable analysis that identified younger age (OR 1.2; p < 0.01), infratentorial tumor location (OR $3 ; \mathrm{p}<0.05)$, and new-onset postoperative hydrocephalus (OR 5.6; $\mathrm{p}<0.01$ ) as being significantly associated with postoperative CSF leaks. ${ }^{8}$

\section{Study Limitations}

Our study had a number of notable limitations. First and foremost, our study was limited to patients who underwent inpatient treatment of their pseudomeningocele. This was a limitation because all postoperative visits in our practice are conducted at facilities apart from where the elective craniotomy took place, each with its own electronic medical records system. Consequently, any patient with a postoperatively detected pseudomeningocele that did not require readmission would not have been captured in this study. We estimate this group of patients with small and self-limiting pseudomeningoceles to be few in number. The effect of not having an "outpatient surveillance system" as part of this study is a lower overall incidence $(5.1 \%, 84 / 1648)$ but a higher intervention $(60 \%, 50 / 84)$ rate compared with the true values.

The low incidence $5 \%$ ) of our outcome of interestclinically significant pseudomeningocele-limited us to bivariate analysis. Results for this retrospective observational study should be considered exploratory and used in a larger study for validation purposes and in order to construct multivariable models to adjust for confounding. Some variables were not explicitly captured in our review, such as the presence of preoperative or postoperative hydrocephalus, However, we did record whether the patient had an existing shunt or had undergone an ETV prior to their elective craniotomy as well as the need for a new shunt or revision of an existing one, which serves as a surrogate for persistent or new-onset altered CSF dynamics postcraniotomy. Raised intracranial pressure, most commonly due to new, persistent, or unrecognized preoperative hydrocephalus, would undoubtedly be a risk factor for pseudomeningocele development and treatment. Other variables that were lacking were the type of dural graft and whether a dural sealant was used. We did not feel that graft type would have an impact on pseudomeningocele development and sealants are used infrequently. Likewise, the presence of temporary CSF diverting devices, such as external ventricular or lumbar drains, was also not recorded, but these too are very rarely used in our elective practice.

As stated previously, there was no standardization for how or when to intervene, and our reasons for intervention may differ from those of other centers, although common indications were CSF leak, overt or suspected postoperative hydrocephalus, and impending wound breakdown. For example, as many of our patients had tumors, having a sizable pseudomeningocele typically prohibits the start of radiation or chemotherapy. Furthermore, we would prefer to repair a pseudomeningocele prior to the onset of any adjuvant therapy. For these two reasons, some of our patients received treatment for pseudomeningoceles that could possibly have resolved with enough time. Additionally, a seroma can masquerade as a pseudomeningocele and would be difficult to distinguish without fluid analysis (i.e., beta-2 transferrin). This is another reason why interventions for early postoperative fluid collections were less common than those for fluid collections that persisted on readmission. Nonetheless, our assumption that a "clinically significant" fluid collection solely represented a pseudomeningocele is an additional study limitation.

\section{Conclusions}

While the literature on cranial pseudomeningoceles is robust, to our knowledge, no previous pediatric study to date has examined factors associated with intervention. Of the variables analyzed in our study, race and use of a dural patch graft were found to have a statistically significant association with intervention for a pseudomeningocele.

\section{Acknowledgments}

We wish to thank Andrew J. Gienapp (Neuroscience Institute, Le Bonheur Children's Hospital, and Department of 
Neurosurgery, University of Tennessee Health Science Center, Memphis, TN) for technical and copy editing, preparation of the manuscript and tables for publishing, and publication assistance. The Jackson Fogelman Pediatric Neurosurgery Research Fund supported this project.

\section{References}

1. Chotai S, Guidry BS, Chan EW, Sborov KD, Gannon S, Shannon C, et al: Unplanned readmission within 90 days after pediatric neurosurgery. J Neurosurg Pediatr 20:542548,2017

2. Cochrane DD, Gustavsson B, Poskitt KP, Steinbok P, Kestle JR: The surgical and natural morbidity of aggressive resection for posterior fossa tumors in childhood. Pediatr Neurosurg 20:19-29, 1994

3. Felbaum DR, Mueller K, Anaizi A, Mason RB, Jean WC, Voyadzis JM: Preservation of the myofascial cuff during posterior fossa surgery to reduce the rate of pseudomeningocele formation and cerebrospinal fluid leak: a technical note. $\mathbf{C u}$ reus 8:e946, 2016

4. Gnanalingham KK, Lafuente J, Thompson D, Harkness W, Hayward R: MRI study of the natural history and risk factors for pseudomeningocoele formation following postfossa surgery in children. Br J Neurosurg 17:530-536, 2003

5. Gnanalingham KK, Lafuente J, Thompson D, Harkness W, Hayward R: Surgical procedures for posterior fossa tumors in children: does craniotomy lead to fewer complications than craniectomy? J Neurosurg 97:821-826, 2002

6. Gopalakrishnan CV, Dhakoji A, Menon G, Nair S: Factors predicting the need for cerebrospinal fluid diversion following posterior fossa tumor surgery in children. Pediatr Neurosurg 48:93-101, 2012

7. Hadanny A, Rozovski U, Nossek E, Shapira Y, Strauss I, Kanner AA, et al: Craniectomy versus craniotomy for posterior fossa metastases: complication profile. World Neurosurg 89:193-198, 2016

8. Hosainey SAM, Lassen B, Helseth E, Meling TR: Cerebrospinal fluid disturbances after 381 consecutive craniotomies for intracranial tumors in pediatric patients. J Neurosurg Pediatr 14:604-614, 2014

9. Hutter G, von Felten S, Sailer MH, Schulz M, Mariani L: Risk factors for postoperative CSF leakage after elective craniotomy and the efficacy of fleece-bound tissue sealing against dural suturing alone: a randomized controlled trial. J Neurosurg 121:735-744, 2014

10. Kinaci A, Algra A, Heuts S, O'Donnell D, van der Zwan A, van Doormaal T: Effectiveness of dural sealants in prevention of cerebrospinal fluid leakage after craniotomy: a systematic review. World Neurosurg 118:368-376.e1, 2018

11. Kshettry VR, Lobo B, Lim J, Sade B, Oya S, Lee JH: Evaluation of non-watertight dural reconstruction with collagen matrix onlay graft in posterior fossa surgery. J Korean Neurosurg Soc 59:52-57, 2016

12. Lassen B, Helseth E, Egge A, Due-Tønnessen BJ, Rønning P, Meling TR: Surgical mortality and selected complications in 273 consecutive craniotomies for intracranial tumors in pediatric patients. Neurosurgery 70:936-943, 2012

13. Lee CK, Mokhtari T, Connolly ID, Li G, Shuer LM, Chang $\mathrm{SD}$, et al: Comparison of porcine and bovine collagen dural substitutes in posterior fossa decompression for Chiari I malformation in adults. World Neurosurg 108:33-40, 2017

14. Legnani FG, Saladino A, Casali C, Vetrano IG, Varisco M, Mattei L, et al: Craniotomy vs. craniectomy for posterior fossa tumors: a prospective study to evaluate complications after surgery. Acta Neurochir (Wien) 155:2281-2286, 2013
15. Mehendale NH, Samy RN, Roland PS: Management of pseudomeningocele following neurotologic procedures. Otolaryngol Head Neck Surg 131:253-262, 2004

16. Menger R, Connor DE Jr, Hefner M, Caldito G, Nanda A: Pseudomeningocele formation following Chiari decompression: 19-year retrospective review of predisposing and prognostic factors. Surg Neurol Int 6:70, 2015

17. Peduzzi P, Concato J, Kemper E, Holford TR, Feinstein AR: A simulation study of the number of events per variable in logistic regression analysis. J Clin Epidemiol 49:1373-1379, 1996

18. Prell J, Scheller C, Alfieri A, Rampp S, Rachinger J: Midlinecraniotomy of the posterior fossa with attached bone flap: experiences in paediatric and adult patients. Acta Neurochir (Wien) 153:541-545, 2011

19. Roth J, Benvenisti H, Constantini S: Watertight dural closure in pediatric craniotomies-is it really necessary? World Neurosurg 114:e743-e746, 2018

20. Sherrod BA, Johnston JM, Rocque BG: Risk factors for unplanned readmission within 30 days after pediatric neurosurgery: a nationwide analysis of 9799 procedures from the American College of Surgeons National Surgical Quality Improvement Program. J Neurosurg Pediatr 18:350-362, 2016

21. Smith GA, Strohl MP, Manjila S, Miller JP: Incidence, management, and outcome of symptomatic postoperative posterior fossa pseudomeningocele: a retrospective single-institution experience. Oper Neurosurg (Hagerstown) 12:298-304, 2016

22. Steinbok P, Singhal A, Mills J, Cochrane DD, Price AV: Cerebrospinal fluid (CSF) leak and pseudomeningocele formation after posterior fossa tumor resection in children: a retrospective analysis. Childs Nerv Syst 23:171-175, 2007

23. Tu A, Tamburrini G, Steinbok P: Management of postoperative pseudomeningoceles: an international survey study. Childs Nerv Syst 30:1791-1801, 2014

24. Wynants L, Bouwmeester W, Moons KG, Moerbeek M, Timmerman D, Van Huffel S, et al: A simulation study of sample size demonstrated the importance of the number of events per variable to develop prediction models in clustered data. J Clin Epidemiol 68:1406-1414, 2015

\section{Disclosures}

The authors report no conflict of interest concerning the materials or methods used in this study or the findings specified in this paper.

\section{Author Contributions}

Conception and design: Klimo. Acquisition of data: Norrdahl, Dave, Vaughn. Analysis and interpretation of data: Norrdahl, Jones. Drafting the article: Klimo, Norrdahl. Critically revising the article: Klimo, Norrdahl, Jones, Hersh. Reviewed submitted version of manuscript: Klimo, Hersh. Approved the final version of the manuscript on behalf of all authors: Klimo. Statistical analysis: Jones.

\section{Correspondence}

Paul Klimo Jr.: Semmes Murphey, Memphis, TN. pklimo@ semmes-murphey.com. 